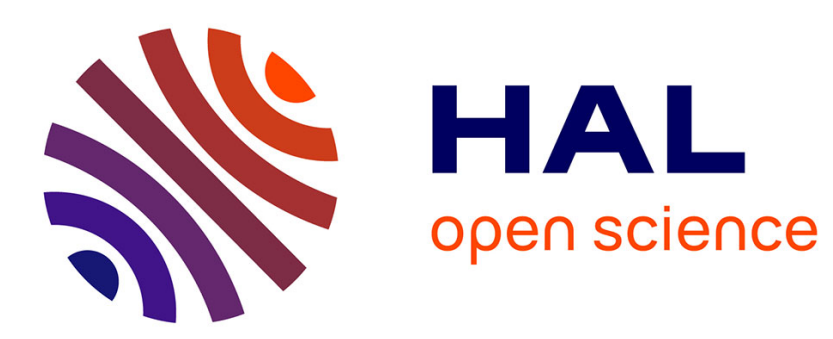

\title{
On the Equivalence of Nash and Evolutionary Equilibrium in Finite Populations
}

Burkhard Hehenkamp, Alex Possajennikov, Tobias Guse

\section{To cite this version:}

Burkhard Hehenkamp, Alex Possajennikov, Tobias Guse. On the Equivalence of Nash and Evolutionary Equilibrium in Finite Populations. Journal of Economic Behavior and Organization, 2009, 73 (2), pp.254. 10.1016/j.jebo.2009.08.011 . hal-00727591

\section{HAL Id: hal-00727591 \\ https://hal.science/hal-00727591}

Submitted on 4 Sep 2012

HAL is a multi-disciplinary open access archive for the deposit and dissemination of scientific research documents, whether they are published or not. The documents may come from teaching and research institutions in France or abroad, or from public or private research centers.
L'archive ouverte pluridisciplinaire HAL, est destinée au dépôt et à la diffusion de documents scientifiques de niveau recherche, publiés ou non, émanant des établissements d'enseignement et de recherche français ou étrangers, des laboratoires publics ou privés. 


\section{Accepted Manuscript}

Title: On the Equivalence of Nash and Evolutionary

Equilibrium in Finite Populations

Authors: Burkhard Hehenkamp, Alex Possajennikov, Tobias

Guse

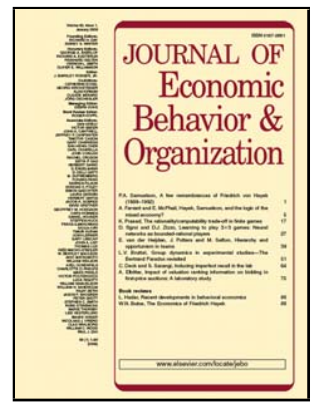

PII:

S0167-2681(09)00215-7

DOI: doi:10.1016/j.jebo.2009.08.011

Reference:

JEBO 2446

To appear in: Journal of Economic Behavior \& Organization

Received date: $\quad 11-4-2008$

Revised date: $\quad 19-8-2009$

Accepted date: $\quad$ 29-8-2009

Please cite this article as: Hehenkamp, B., Possajennikov, A., Guse, T., On the Equivalence of Nash and Evolutionary Equilibrium in Finite Populations, Journal of Economic Behavior and Organization (2008), doi:10.1016/j.jebo.2009.08.011

This is a PDF file of an unedited manuscript that has been accepted for publication. As a service to our customers we are providing this early version of the manuscript. The manuscript will undergo copyediting, typesetting, and review of the resulting proof before it is published in its final form. Please note that during the production process errors may be discovered which could affect the content, and all legal disclaimers that apply to the journal pertain. 


\title{
On the Equivalence of Nash and Evolutionary Equilibrium in Finite Populations
}

\author{
Burkhard Hehenkamp* \\ Alex Possajennikov ${ }^{\dagger}$ \\ University of Dortmund \\ University of Nottingham \\ with Tobias Guse \\ University of Dortmund
}

August 2009

First submission: April 2008

\begin{abstract}
This paper provides sufficient and partially necessary conditions for the equivalence of symmetric Nash and evolutionary equilibrium in symmetric games played by finite populations. The conditions are based on generalized constant-sum and "smallness" properties, the latter of which is known from models of perfect competition and large games. The conditions are illustrated on examples including oligopoly games.
\end{abstract}

Keywords: Nash equilibrium, Evolutionary stability, Finite populations

JEL Codes: C72, C73

${ }^{*}$ Corresponding Author. Department of Economics and Social Sciences, University of Dortmund, Vogelpothsweg 87, 44221 Dortmund, Germany. Tel.: +49-231-755-3215. Fax: +49-231-755-3027. E-mail: burkhard.hehenkamp@udo.edu.

†School of Economics, University of Nottingham, University Park, Nottingham NG7 2RD, United Kingdom.

$\ddagger$ Tobias contributed at the early stages of the project but later decided to leave it. 


\title{
On the Equivalence of Nash and Evolutionary Equilibrium in Finite Populations
}

\author{
August 2009
}

First submission: April 2008

\begin{abstract}
This paper provides sufficient and partially necessary conditions for the equivalence of symmetric Nash and evolutionary equilibrium in symmetric games played by finite populations. The conditions are based on generalized constant-sum and "smallness" properties, the latter of which is known from models of perfect competition and large games. The conditions are illustrated on examples including oligopoly games.
\end{abstract}

Keywords: Nash equilibrium, Evolutionary stability, Finite populations

JEL Codes: C72, C73

\section{Equilibrium and evolution}

The concept of Nash equilibrium (NE) is a cornerstone of game theory. From a dynamic point of view, (some) Nash equilibria can be justified by evolutionary processes, which usually appeal to an infinitely large population of players. A reduction of such a dynamic approach to a static equilibrium notion is conceptualized in the evolutionarily stable strategy (ESS; Maynard Smith and Price, 1973).

Schaffer (1989) proposed an adaptation of the ESS concept to a finite population of players, calling it (symmetric) evolutionary equilibrium (EE). ${ }^{1}$ Dynamic foundations for the EE concept were discussed in Schaffer (1989)

\footnotetext{
${ }^{1}$ In an earlier paper, Schaffer (1988) introduces the concept of a generalized ESS, which consists of an equilibrium condition and a stability condition. The equilibrium condition defines the EE concept.
} 
and further support for it under imitation dynamics is provided by VegaRedondo (1997) and Alós-Ferrer and Ania (2005a).

Schaffer (1989) and others (e.g. Vega-Redondo, 1996, Ch. 2; Tanaka, 2000; Hehenkamp et al., 2004) have shown that evolutionary equilibria generally differ from Nash equilibria, illustrating this on the examples of quantity and price oligopolies, and rent-seeking games. The reason for the difference is that in EE players maximize relative payoffs. Nevertheless, there are games in which EE and NE are related (e.g. Alós-Ferrer and Ania, 2005b). Ania (2008) identifies constant-sum games and games with weak payoff externalities as classes of games where EE and NE predictions coincide. ${ }^{2}$

We ask how far one can go to generalize the previous results on the equivalence, or difference, of evolutionary and Nash equilibria. We provide sufficient and partially necessary conditions on the payoff function for a symmetric game to have sets of EE and NE coincide. Our first theorem extends Ania's (2008) result. It is sufficient for the equivalence of $\mathrm{EE}$ and NE, that a game exhibits versions of competitiveness (which generalizes constant-sum), or of weak payoff externality properties at symmetric strategy profiles. Each profile needs to satisfy only one of the properties for unilateral deviations, and for non-equilibrium profiles only profitable deviations need to be considered. Our second theorem shows that these two properties are also necessary for the equivalence, at least at equilibrium profiles.

We illustrate the economic relevance of our results by means of examples, including Bertrand competition with constant unit cost and games with continuous payoff functions, which cover other oligopoly games.

\section{Definitions and notation}

We investigate a model where a set $I=\{1, \ldots, n\}$ of individuals play a symmetric $n$-person game $\Gamma=\left(I,\left\{X_{i}\right\}_{i=I},\left\{\pi_{i}\right\}_{i=I}\right\}$, where $X_{i}$ denotes the strategy set of player $i, X:=\times_{i=1}^{n} X_{i}$ the set of joint strategies profiles, and $\pi_{i}: X \rightarrow \mathbb{R}$ denotes the payoff function of player $i$. Symmetry requires that the strategy sets of the players coincide $\left(X_{i}=X_{j}\right.$ for all $\left.i, j\right)$, and that the payoff functions satisfy $\pi_{i}\left(x_{1}, \ldots, x_{n}\right)=\pi_{\rho(i)}\left(x_{\rho(1)}, \ldots, x_{\rho(n)}\right)$ for any permutation $\rho$ of $I$. We do not impose any further assumptions on $X$ or on $\pi_{i}$. Let $\mathcal{G}$ denote the class of games under consideration and let $[a]^{k}$ denote object $a$ repeated $k$ times, i.e. $[a]^{k}=a, .{ }^{k}, a$.

A symmetric strategy profile $x=\left([a]^{n}\right)$ is a symmetric pure Nash equilib-

\footnotetext{
${ }^{2}$ Schaffer (1989) observed that EE would be the same as NE in games without strategic interaction and in zero-sum games.
} 
rium of game $\Gamma$ if

$$
\pi_{1}\left(a,[a]^{n-1}\right) \geq \pi_{1}\left(b,[a]^{n-1}\right) \text { for all } b \in X_{1} .
$$

The set of all symmetric pure Nash equilibria in game $\Gamma$ is denoted by $X^{N}$.

We call a symmetric strategy profile $x=\left([a]^{n}\right)$ an evolutionary equilibrium of game $\Gamma$ if

$$
\pi_{1}\left([a]^{n-1}, b\right) \geq \pi_{1}\left(b,[a]^{n-1}\right) \text { for all } b \in X_{1} .
$$

The set of all evolutionary equilibria in game $\Gamma$ is denoted by $X^{E}$.

By symmetry of the game, we have $\pi_{1}\left([a]^{n-1}, b\right)=\pi_{i}\left(b,[a]^{n-1}\right)$ for all $i \neq 1$. Accordingly, the latter definition compares payoffs of different players after a deviation by one player from $a$ to $b$. In the evolutionary interpretation, if a deviator to $b$ has higher payoff than the players that stay at $a$, then $a$ is not viable and thus $\left([a]^{n}\right)$ cannot constitute an evolutionary equilibrium.

Let $x \in X$ be an arbitrary strategy profile and let $x^{i}$ denote the profile in which $x_{i}^{i} \neq x_{i}$, while $x_{j}^{i}=x_{j}$ for $j \neq i$, i.e. $x^{i}=\left(x_{1}, \ldots, x_{i-1}, x_{i}^{i}, x_{i+1}, \ldots, x_{n}\right)$.

Consider a game $\Gamma \in \mathcal{G}$. We say (a) game $\Gamma$ has a weak payoff externality between $x$ and $x^{i}$ and between players $i$ and $j$ if

$$
\left|\pi_{i}(x)-\pi_{i}\left(x^{i}\right)\right|>\left|\pi_{j}(x)-\pi_{j}\left(x^{i}\right)\right|
$$

and (b) game $\Gamma$ has weak payoff externalities if (WPE) holds for all $x, x^{i}$ and for all pairs of players $(i, j), j \neq i$.

The concept of weak payoff externality appears in Ania (2008), who uses the global part (b) of the definition. The concept means that when player $i$ changes strategy, the effect on his/her own payoff is larger than the effect on the payoff of any other player $j$. Weak payoff externality can be seen as a generalization of the "smallness" property in large games or competitive markets where a player cannot affect others' payoffs by much.

We say (a) game $\Gamma$ is weakly competitive between $x$ and $x^{i}$ and between players $i$ and $j$ if

$$
\begin{aligned}
& \pi_{i}(x)-\pi_{i}\left(x^{i}\right) \geq 0 \Rightarrow \pi_{j}(x)-\pi_{j}\left(x^{i}\right) \leq 0 \text { and } \\
& \pi_{i}(x)-\pi_{i}\left(x^{i}\right)<0 \Rightarrow \pi_{j}(x)-\pi_{j}\left(x^{i}\right) \geq 0
\end{aligned}
$$

and (b) game $\Gamma$ is weakly competitive if for all $x, x^{i}$ and all players $i$, there exists player $j \neq i$ such that (WC) holds.

The definition extends the notion of a strictly competitive game to the general $n$-player case, $n \geq 2 .^{3}$ If player $i$ wins from a deviation, then at least one other player does not win. If player $i$ loses from a deviation, at least

\footnotetext{
${ }^{3}$ See e.g. Friedman (1990, Ch. 3).
} 
one player does not lose. Observe that the class of weakly competitive games includes constant-sum games as a special case.

Parts (b) of the two definitions require the respective property to hold globally in a game. For our purposes it will be sufficient that the properties hold locally between symmetric profiles and some unilateral deviations from them.

\section{Sufficient conditions for equilibrium equiv- alence}

Our first result provides sufficient conditions for the equivalence of Nash and evolutionary equilibria.

Theorem 1 Consider game $\Gamma \in \mathcal{G}$. Suppose that for each $x=\left([a]^{n}\right)$ :

i) if $x \in X^{N}$, then (WPE) or (WC) (or both) hold between $x$ and $x^{1}=$ $\left(b,[a]^{n-1}\right)$ for players 1 and $i, i \neq 1$, for all $b$;

ii) if $x \notin X^{N}$ then (WPE) or (WC) (or both) hold between $x$ and $x^{1}=$ $\left(b,[a]^{n-1}\right)$ for players 1 and $i, i \neq 1$, for all $b$ such that $\pi_{1}\left(b,[a]^{n-1}\right)>$ $\pi_{1}\left([a]^{n}\right)$.

Then the sets of symmetric pure Nash equilibria and evolutionary equilibria coincide, i.e. $X^{N}=X^{E}$.

Proof. Consider $x=\left([a]^{n}\right) \in X^{N}$ so that (WPE) or (WC) holds between $x$ and $x^{1}=\left(b,[a]^{n-1}\right)$ for all $b$. Suppose $x \notin X^{E}$. Then there exists $b \neq a$ such that $\pi_{1}\left(b,[a]^{n-1}\right)>\pi_{1}\left([a]^{n-1}, b\right)$ and hence $\pi_{1}\left([a]^{n}\right)-\pi_{1}\left(b,[a]^{n-1}\right)<$ $\pi_{1}\left([a]^{n}\right)-\pi_{1}\left([a]^{n-1}, b\right)$. Since $x \in X^{N}$, the left-hand side is non-negative. By symmetry, $0 \leq \pi_{1}\left([a]^{n}\right)-\pi_{1}\left(b,[a]^{n-1}\right)<\pi_{i}\left([a]^{n}\right)-\pi_{i}\left(b,[a]^{n-1}\right)$ for $i \neq 1$, which violates both (WPE) and (WC). Thus $x \in X^{E}$.

Consider now $x=\left([a]^{n}\right) \notin X^{N}$ so that (WPE) or (WC) holds between $x$ and $x^{1}=\left(b,[a]^{n-1}\right)$ such that $\pi_{1}\left(b,[a]^{n-1}\right)>\pi_{1}\left([a]^{n}\right)$. Such $b$ exists because of $x \notin X^{N}$. Suppose $x \in X^{E}$. Then $\pi_{1}\left([a]^{n-1}, b^{\prime}\right) \geq \pi_{1}\left(b^{\prime},[a]^{n-1}\right)$ for all $b^{\prime}$, and thus $\pi_{1}\left(b,[a]^{n-1}\right)-\pi_{1}\left([a]^{n}\right) \leq \pi_{1}\left([a]^{n-1}, b\right)-\pi_{1}\left([a]^{n}\right)$. By symmetry of the game, $0<\pi_{1}\left(b,[a]^{n-1}\right)-\pi_{1}\left([a]^{n}\right) \leq \pi_{i}\left(b,[a]^{n-1}\right)-\pi_{i}\left([a]^{n}\right)$ for $i \neq 1$, which contradicts (WPE) and (WC). Thus $x \notin X^{E}$.

Corollary 1 Let $\Gamma \in \mathcal{G}$ be weakly competitive. Then $X^{N}=X^{E}$. 
The theorem generalizes the results in Ania (2008, Propositions 1 and 2 ) in three ways. First, the constant-sum property is replaced by the much weaker property of weak competitiveness. Second, the properties of weak competitiveness and weak payoff externalities need to hold only at symmetric strategy profiles, and for profiles that are not Nash equilibria, only for profitable one-player deviations. Third, the two properties can be locally substituted for each other. Accordingly, the theorem also covers games that neither are weakly competitive nor display weak payoff externalities globally, but that locally possess a mixture of the two properties. The following examples illustrate this.

Example 1 A Game that is neither weakly competitive nor has weak payoff externalities, but that satisfies the assumptions of Theorem 1.

Consider the symmetric three-person game with payoff matrices (Player 3 chooses between matrices)

\begin{tabular}{|c|c|c|}
\multicolumn{1}{c|}{} & \multicolumn{2}{c|}{$3: \alpha$} \\
\hline $1 \backslash 2$ & $\alpha$ & $\beta$ \\
\hline$\alpha$ & $1,1,1$ & $3,0,3$ \\
\hline$\beta$ & $0,3,3$ & $6,6,9$ \\
\hline
\end{tabular}

\begin{tabular}{|c|c|c|}
\multicolumn{1}{c|}{} & \multicolumn{2}{c|}{$3: \beta$} \\
\hline $1 \backslash 2$ & $\alpha$ & $\beta$ \\
\hline$\alpha$ & $3,3,0$ & $9,6,6$ \\
\hline$\beta$ & $6,9,6$ & $5,5,5$ \\
\hline
\end{tabular}

Profiles $(\alpha, \alpha, \beta)$ with payoffs $(3,3,0)$, and $(\beta, \alpha, \beta)$ with payoffs $(6,9,6)$, satisfy neither (WPE) nor (WC). Furthermore, $(\alpha, \alpha, \alpha)$ and $(\beta, \alpha, \alpha)$ violate (WPE) but satisfy (WC), and $(\beta, \beta, \beta)$ and $(\alpha, \beta, \beta)$ violate (WC) but satisfy (WPE). The game is neither weakly competitive nor does it have weak payoff externalities, but by Theorem 1 we have $X^{N}=X^{E}(=\{(\alpha, \alpha, \alpha)\})$.

Example 2 Bertrand oligopoly with constant unit cost.

Consider a symmetric $n$-firm Bertrand oligopoly with market demand $Q(p)$ and cost function $C_{i}\left(q_{i}\right)=c q_{i}$, for all $i=1, \ldots, n$. Firms set prices $p_{i} \geq$ 0 and market demand is shared equally between all firms that charge the lowest price $p^{\min }=\min _{i} p_{i}$. If $k$ is the number of firms charging the lowest price, then $q_{i}\left(p_{1}, \ldots, p_{n}\right)=Q\left(p^{\text {min }}\right) / k$ when $p_{i}=p^{\text {min }}$, and $q_{i}\left(p_{1}, \ldots, p_{n}\right)=0$ otherwise. Firm $i$ 's profit function is $\pi_{i}\left(p_{1}, \ldots, p_{n}\right)=q_{i}\left(p_{1}, \ldots, p_{n}\right)\left(p_{i}-c\right)$. Under standard assumptions, there exists a unique symmetric Bertrand equilibrium so that $X^{N}=\{(c, \ldots, c)\}$.

From the equilibrium profile, any unilateral price reduction changes only the payoff of the deviating firm, thus (WPE) is satisfied. Any unilateral price increase satisfies (WC). From symmetric profiles with prices below marginal cost, any deviation is weakly competitive. From symmetric profiles 
with prices above marginal cost, a unilateral profitable price reduction makes the payoff of all other firms drop to zero. Thus such a deviation is weakly competitive. Theorem 1 therefore implies that $X^{E}=X^{N}=\{(c, \ldots, c)\}$.

Note that a weaker version of Theorem 1 requiring one of the properties to hold for all one-player deviations from symmetric profiles would not be sufficient to claim the result because a non-profitable reduction involving a price above marginal cost satisfies neither (WPE) nor (WC).

\section{Necessary conditions for equilibrium equiv- alence}

The second result identifies necessary conditions for the equivalence of Nash and evolutionary equilibrium in games that are generic in a certain sense.

Theorem 2 Let $\Gamma \in \mathcal{G}$ be such that $b \neq a$ implies $\pi_{1}\left(b,[a]^{n-1}\right) \neq \pi_{1}\left([a]^{n}\right)$ and $\pi_{1}\left(b,[a]^{n-1}\right) \neq \pi_{i}\left(b,[a]^{n-1}\right)$ for all $i \neq 1$. Suppose that $X^{N}=X^{E}$. Then for each $x=\left([a]^{n}\right)$ :

i) if $x \in X^{N}=X^{E}$, then (WPE) or (WC) (or both) hold between $x$ and $x^{1}=\left(b,[a]^{n-1}\right)$ for players 1 and $i, i \neq 1$ for all $b$;

ii) if $x \notin X^{N}=X^{E}$, then (WPE) or (WC) (or both) hold between $x$ and $x^{1}=\left(b,[a]^{n-1}\right)$ for players 1 and $i, i \neq 1$ for some $b$ such that $\pi_{1}\left(b,[a]^{n-1}\right)>\pi_{1}\left([a]^{n}\right)$, and (WC) or not (WPE) hold for some $b$ such that $\pi_{1}\left(b,[a]^{n-1}\right)<\pi_{1}\left([a]^{n}\right)$ if such $b$ exist.

Proof. Consider $x=\left([a]^{n}\right) \in X^{N}=X^{E}$. By genericity $\pi_{1}(x)>\pi_{1}\left(x^{1}\right)$ and $\pi_{1}\left([a]^{n-1}, b\right)>\pi_{1}\left(x^{1}\right)$ for any $x^{1}=\left(b,[a]^{n-1}\right)$ with $b \neq a$. Hence, by symmetry

$$
\pi_{1}(x)-\pi_{1}\left(x^{1}\right)>\pi_{1}(x)-\pi_{1}\left([a]^{n-1}, b\right)=\pi_{i}(x)-\pi_{i}\left(x^{1}\right) \text { for } i \neq 1 .
$$

If $\pi_{i}(x)-\pi_{i}\left(x^{1}\right) \geq 0$, then (WPE) is satisfied between $x$ and $x^{1}$. If $\pi_{i}(x)-$ $\pi_{i}\left(x^{1}\right)<0$, then (WC) is satisfied between $x$ and $x^{1}$.

Consider $x=\left([a]^{n}\right) \notin X^{N}=X^{E}$. Suppose that both (WPE) and (WC) are violated between $x$ and $x^{1}=\left(b,[a]^{n-1}\right)$ for all $b$ such that $\pi_{1}\left(b,[a]^{n-1}\right)>$ $\pi_{1}\left([a]^{n}\right)$ (such $b$ exists because $\left.x \notin X^{N}\right)$. Since (WC) is violated, $\pi_{i}\left([a]^{n}\right)-$ $\pi_{i}\left(b,[a]^{n-1}\right)<0$ for $i \neq 1$ and such $b$. Since (WPE) is violated, $\pi_{1}\left(b,[a]^{n-1}\right)-$ $\pi_{1}\left([a]^{n}\right) \leq \pi_{i}\left(b,[a]^{n-1}\right)-\pi_{i}\left([a]^{n}\right)$ for $i \neq 1$ and such $b$. By symmetry, the inequality is equivalent to $\pi_{1}\left(b,[a]^{n-1}\right) \leq \pi_{1}\left([a]^{n-1}, b\right)$ for all such $b$. 
Suppose now that (WC) is violated and (WPE) holds for all $b$ such that $\pi_{1}\left(b,[a]^{n-1}\right)<\pi_{1}\left([a]^{n}\right)$. Then $\pi_{i}\left([a]^{n}\right)-\pi_{i}\left(b,[a]^{n-1}\right)>0$ for $i \neq 1$ and such $b$, and $\pi_{1}\left([a]^{n}\right)-\pi_{1}\left(b,[a]^{n-1}\right)>\pi_{i}\left([a]^{n}\right)-\pi_{i}\left(b,[a]^{n-1}\right)$ for $i \neq 1$ and such $b$. The last inequality implies $\pi_{1}\left(b,[a]^{n-1}\right)<\pi_{i}\left(b,[a]^{n-1}\right)=\pi_{1}\left([a]^{n-1}, b\right)$ for all such $b$. Thus this inequality holds for all $b$, which contradicts $x \notin X^{E}$.

The theorem provides means to argue that a given game has evolutionary equilibria different from Nash equilibria. If Nash equilibria (or some characterization of them) of the game are known, one method is to show that for a given Nash equilibrium both (WPE) and (WC) are violated for some $b$. Without knowing the equilibria, one way to show that equilibrium equivalence fails is to show that both (WPE) and (WC) are violated for some $b$ for all symmetric profiles. Alternatively, one can use condition ii) of the theorem to find a symmetric profile for which (WC) is violated for all $b$, and (WPE) is violated for all $b$ such that $\pi_{1}\left(b,[a]^{n-1}\right)>\pi_{1}\left([a]^{n}\right)$, while it holds for all $b$ such that $\pi_{1}\left(b,[a]^{n-1}\right)<\pi_{1}\left([a]^{n}\right)$. The corollary and the example below illustrate these cases.

Corollary 2 Let $\Gamma \in \mathcal{G}$ be a game with continuous strategy sets $X_{i} \subset \mathbb{R}$ and differentiable payoff functions $\pi_{i}: X \rightarrow \mathbb{R}$. Let $x \in X^{N}$ represent an isolated interior Nash equilibrium. Then $\frac{\partial \pi_{j}}{\partial x_{i}}(x) \neq 0$ implies $X^{E} \neq X^{N}$.

Proof. Since at equilibrium $\frac{\partial \pi_{i}}{\partial x_{i}}(x)=0$, for sufficiently small deviations from $x$ (WPE) is violated if $\frac{\partial \pi_{j}}{\partial x_{i}}(x) \neq 0$. Depending on the sign of $\frac{\partial \pi_{j}}{\partial x_{i}}(x)$, (WC) is violated between $x=\left([a]^{n}\right)$ and $x^{1}=\left(b,[a]^{n-1}\right)$ either for $b>a$ or for $b<a$.

The corollary covers continuous games such as Cournot oligopoly or rentseeking contests. In these games, the failure of equivalence is a direct consequence of negative spillovers. ${ }^{4}$

\footnotetext{
${ }^{4} \mathrm{~A}$ game has negative (positive) spillovers if a larger own action (e.g. quantity or expenditure) reduces (increases) the opponents' payoffs. A similar result applies to games with positive spillovers.
} 
Example 3 A Game with the necessary condition ii) violated.

Consider the symmetric two-player game with payoff matrix

\begin{tabular}{|c|c|c|c|}
\hline & $\alpha$ & $\beta$ & $\gamma$ \\
\hline$\alpha$ & 2,2 & 3,4 & 2,3 \\
\hline$\beta$ & 4,3 & 2,2 & 1,0 \\
\hline$\gamma$ & 3,2 & 0,1 & 0,0 \\
\hline
\end{tabular}

In this game, $(\mathrm{WC})$ is violated for all deviations from $(\beta, \beta)$. Also, $\pi_{1}(\alpha, \beta)>$ $\pi_{1}(\beta, \beta)$ and (WPE) is violated between $(\beta, \beta)$ and $(\alpha, \beta)$, and $\pi_{1}(\gamma, \beta)<$ $\pi_{1}(\beta, \beta)$ and (WPE) holds between $(\beta, \beta)$ and $(\gamma, \beta)$. Thus $X^{E} \neq X^{N}$ (in fact, $X^{E}=\{(\beta, \beta)\}$ and $\left.X^{N}=\varnothing\right)$.

\section{Conclusion}

The sets of symmetric evolutionary equilibria and symmetric Nash equilibria in pure strategies coincide for games that are weakly competitive, or that display weak payoff externalities at symmetric strategy profiles. These properties can be locally substituted one for the other, and it is sufficient that they apply only to profitable deviations from non-Nash profiles (Theorem 1). Although the corresponding class of games may appear narrow, it contains such important classes of games as constant-sum, strictly competitive, and non-atomic games. Bertrand oligopoly with constant unit costs represents an economic example where the full force of the extensions is required to establish equilibrium equivalence.

For generic games, the two properties are not only sufficient for equilibrium equivalence, but at least one of them is also necessary at equilibrium profiles and partially necessary at other profiles (Theorem 2). Therefore, the sufficient conditions of weak payoff externalities and weak competitiveness (and local combinations thereof) essentially exhaust the properties on (generic) games for which equilibrium equivalence can be expected.

\section{References}

[1] Alós-Ferrer, C., Ania, A.B., 2005a. The evolutionary stability of perfectly competitive behavior. Economic Theory 26, 497-516.

[2] Alós-Ferrer, C., Ania, A.B., 2005b. The asset market game. Journal of Mathematical Economics 41, 67-90. 
[3] Ania, A.B., 2008. Evolutionary stability and Nash equilibrium in finite populations, with an application to price competition. Journal of Economic Behavior \& Organization 65, 472-488.

[4] Friedman, J.W., 1990. Game Theory with Applications to Economics. 2nd edition. Oxford University Press, Oxford.

[5] Hehenkamp, B., Leininger, W., Possajennikov, A., 2004. Evolutionary equilibrium in Tullock contests: Spite and overdissipation. European Journal of Political Economy 20, 1045-1057.

[6] Maynard Smith, J., Price, G.R., 1973. The logic of animal conflict. Nature 246, 15-18.

[7] Schaffer, M.E., 1988. Evolutionarily stable strategies for a finite population and a variable contest size. Journal of Theoretical Biology 132, 469-478.

[8] Schaffer, M.E., 1989. Are profit maximisers the best survivors? Journal of Economic Behavior \& Organization 12, 29-45.

[9] Tanaka, Y., 2000. Stochastically stable states in oligopoly with differentiated goods: Equivalence of price and quantity strategies, Journal of Mathematical Economics 34, 235-253.

[10] Vega-Redondo, F., 1996. Evolution, Games, and Economic Behavior. Oxford University Press, Oxford.

[11] Vega-Redondo, F., 1997. The evolution of Walrasian behavior. Econometrica $65,375-384$. 